\title{
Reading and Deafness: State of the Evidence and Implications for Research and Practice
}

\author{
Beverly Trezek ${ }^{1, *}$ and Connie Mayer ${ }^{2}$ \\ 1 School of Education, University of Wisconsin-Madison, 1000 Bascom Mall, Madison, WI 53706, USA \\ 2 Faculty of Education, York University, Toronto, ON M3J 1P3, Canada \\ * Correspondence: bjtrezek@wisc.edu
}

Received: 29 April 2019; Accepted: 7 August 2019; Published: 14 August 2019

\begin{abstract}
Over the years, persistently low achievement levels have led scholars to question whether reading skill development is different for deaf readers. Research findings suggest that in order for deaf students to become proficient readers, they must master the same fundamental abilities that are well established for hearing learners, regardless of the degree of hearing loss or communication modality used (e.g., spoken or signed). The simple view of reading (SVR), which hypothesizes the critical role both language abilities and phonological skills play in development of reading comprehension, provides a model for understanding the reading process for a wide range of students and has the potential to shed light on the challenges deaf students have historically experienced in achieving age-appropriate outcomes. Therefore, the purpose of this paper is to review the components of the SVR and use this conceptual model as the basis for exploring and discussing both historical and current research evidence in reading and deafness, with a particular focus on phonological skills. Recommendations for future research and practice based on the existing body of literature will also be provided.
\end{abstract}

Keywords: deaf; reading development; simple view of reading; reading instruction; reading interventions

\section{Introduction}

Deaf learners have historically faced challenges in achieving reading outcomes commensurate with their hearing peers. Specifically, outcome data have consistently indicated significant delays in achievement among this population of students, with a reported median fourth-grade reading level for high school graduates [1]. Over the years, these persistently low achievement levels have led scholars to question whether reading skill development is different for deaf readers (see [2,3] for discussions). In a seminal discussion of this topic, Hanson [4] directly explored the question, "Is reading different for deaf individuals?" (p. 85). Based on the evidence available at the time, rather than a yes or no answer, a dual response to this question was offered. Hanson suggested that even though deaf learners often bring a different set of language experiences to the task of reading, the fundamental task of reading remains the same. Like their hearing peers, they need to rely on an understanding and application of both English language and phonology when reading (see also [5]).

A contemporary interpretation of Hanson's [4] dual response is reflected in the qualitative similarity hypothesis (QSH) proffered by Paul and colleagues [6-10]. According to the QSH, deaf children follow a qualitatively similar developmental learning trajectory to that of hearing students, even though the development of skills may be quantitatively delayed. Furthermore, becoming a proficient reader depends upon mastering the same fundamental abilities that are well established for hearing learners, regardless of the degree of hearing loss or communication modality used (e.g., spoken or signed). In discussing conventional literacy skills specifically, Paul, Wang, and Williams [10] recognized the 
importance of the ability "to decode and encode written language to attain or construct meaning" (p. 90) as well as apply strategies to both comprehend and create text. While the authors acknowledged a number of current literacy theories (e.g., constructivism, cognitivism, cognitive-processing, social learning), and the influence each may have on interpreting the nature of skill development, the specific abilities explicated when describing the QSH (e.g., word recognition, orthographic processing, vocabulary development, fluency, reading comprehension instruction, phonology, and phonological processing) were not directly tied to a specific framework or theory.

Considering the aforementioned skills, [10] we see this perspective closely aligned with the Simple View of Reading (SVR) [11], which establishes the critical role that both language and phonological skills play in the development of reading comprehension abilities. While it has been suggested that the SVR "is neither a full theory of reading nor a blueprint for instruction" [12] (p. 75), it has become a widely accepted framework for understanding the abilities required for developing reading competencies, explaining reading challenges and disabilities, assessing prerequisite skills and reading outcomes, and selecting appropriate instructional interventions to meet students' identified needs. Given the strong theoretical and empirical base for the SVR, coupled with the insights garnered regarding students with reading disabilities as part of its development, we contend that the SVR provides a model for understanding the reading process among a wide-range of students, including those who are deaf, and serves as an appropriate framework for explaining development within the context of the QSH.

The benefit of explicitly interpreting the QSH [10] in light of the SVR [11] is that it provides the opportunity to draw upon the research findings associated with this model, relate them to the existing literature in reading and deafness, and identify areas of future research that can be enhanced by employing similar research methodologies used to evaluate the SVR. As such, we will begin by providing a review of the components of the SVR, a brief overview of the research evidence supporting it, and a discussion of current interpretations of this framework in the field of literacy more broadly. Drawing upon both historical and current research in reading and deafness, we will summarize findings, discuss them within the context of the SVR framework, and offer implications for future research and practice based on the available evidence.

\section{Simple View of Reading (SVR)}

More than 30 years ago, Gough and Tunmer [11] proposed the SVR to describe the components and process involved in the development of reading. According to this model, reading comprehension relies on two, interdependent processes-decoding and language comprehension. Broadly defined, reading comprehension is the ability to construct meaning from language represented in print, whereas language comprehension involves the ability to derive an understanding of linguistic information presented through oral language. Decoding involves the ability to recognize words in print with sufficient automaticity to provide access to the proper meaning within the learner's mental lexicon $[11,13]$.

It is noteworthy that the SVR was conceptualized during the height of the 'reading wars' when opinions regarding the development of reading and instructional strategies to support achievement were extremely polarized, with proponents of decoding (phonics) on one side and advocates for comprehension (whole language) on the other [14,15]. Because of this, some consider the creation of the SVR an attempt to bring about balance in the field by developing a model that recognized the contributions of both decoding and comprehension in the reading process (see [12] for discussion). Given the contentious debates surrounding reading at that time, and the on-going debates in the field of reading and deafness, it is important to further explore the terminology used in describing the key components of the SVR, particularly the term decoding.

\subsection{Decoding}

For some, the word decoding is synonymous with applying the alphabetic principle, or the understanding that there is a systematic and predictable relationship between letters and sounds, to read individual words ('sounding out'), whereas others equate decoding with context-free word 
recognition. In clarifying their definition, Gough and Tunmer [11] suggested that decoding in an alphabetic language such as English relies heavily on the "orthographic cipher" (p. 7), or knowledge of grapheme-phoneme relations, to read words quickly, accurately, and silently. This definition of decoding highlights the role of automaticity in the process of applying the alphabetic principle to word reading (quickly and silently) and the importance of activating meanings from the mental lexicon (accurately).

Despite a strong emphasis on the application of alphabetic coding or phonics, the fact that knowledge of the cipher alone would be insufficient to support the ability to recognize phonetically irregular (e.g., said, was) or orthographically ambiguous (e.g., meat, leather) words was recognized, albeit with the caveat that developing alphabetic decoding skills would enable beginning readers to access a large number of English words [11]. As such, it has been suggested that the term 'decoding' was selected over 'word recognition' to emphasize the importance of alphabetic coding as the foundation for word reading, as phonics was at the center of the debates at the time the SVR was proposed [13].

\subsection{Language Comprehension}

Within the original iteration of the SVR model, the term comprehension was used to refer to linguistic comprehension, or the process used to interpret words, sentences, and connected discourse [11]. However, in more recent descriptions of the SVR, the term language comprehension has been used to denote these abilities [13]. Some researchers have argued that the processes involved in reading differ from those required for language. However, Gough and Tunmer [11] suggested that these activities are parallel processes, although it was acknowledged that additional skills such as eye movements are involved in reading. In other words, once words have been accurately decoded, an individual engages the same processes to understand what is read as those that would be used to comprehend oral language.

\subsection{Application of the SVR Components}

Within the SVR model, reading comprehension (R) is considered the product of decoding (D) and language comprehension (C). Using the simple equation $\mathrm{R}=\mathrm{D} \times \mathrm{C}$, Gough and Tunmer [11] explained that each variable could range from 0 (nullity) to 1 (perfection). The formula was then used to illustrate the notion that both decoding and language comprehension are necessary components, but alone are not sufficient, for reading comprehension to occur. In other words, without the skills to decode $(\mathrm{R}=\mathrm{D} \times \mathrm{C}$ with $\mathrm{D}=0)$, no amount of language comprehension can compensate for a lack of decoding ability $(\mathrm{R}=0)$. Similarly, if an individual is able to decode words but is unable to comprehend $(R=D \times C$ with $C=0)$, then reading is not taking place $(R=0)$.

Using a range of measures to assess skills in the domains of decoding (e.g., letter knowledge, print knowledge, phonological awareness, rapid automatized naming or RAN, word identification, word attack) and language comprehension (e.g., expressive and receptive vocabulary, vocabulary depth, expressive and receptive syntax), findings of studies have consistently demonstrated the contributions of the two components to reading comprehension (see [13] for discussion). While the research has also demonstrated the differential contributions of decoding and language comprehension to reading comprehension at specific points within the developmental process, the SVR does not predict that as one relation becomes stronger (e.g., relation between language comprehension and reading comprehension) the other becomes weaker (e.g., relation between decoding and reading comprehension). Rather, it has been suggested that if skill in one component reaches perfection, the level of skill in the other will likely determine the level of reading comprehension ability [13]. This explanation may account for the demonstrated increase in the role of language comprehension in reading comprehension over time, as decoding is considered a constrained skill that is typically mastered by the age of eight [16], whereas language continues to grow throughout the school years and arguably across the life span $[13,15]$.

When developing the SVR, Gough and Tunmer [11] acknowledged the relation between process and instruction but were primarily interested in creating a model to explain the extent to which 
decoding skills were implicated in the development of reading. More specifically, the goal was to explicate three types of reading disabilities that were the result of challenges stemming from: (1) Decoding (i.e., dyslexia), (2) comprehension (i.e., hyperlexia), or (3) a combination of decoding and comprehension (i.e., garden-variety reading disability). The theoretical foundation for the SVR is further bolstered by Chall's [15] reading scheme that was developed during the same era. Within this model, it was hypothesized that an interaction between bottom-up, code-related skills (decoding) and top-down, language-related abilities (language comprehension) is required in order for readers to comprehend texts. While the SVR and Chall's schema share a similar conceptual base, Chall also took into account readers' interactions with their environment and the specific instructional strategies to support skill development across six, hierarchical stages from preschool through college. In other words, in Chall's cognitive information-processing model, reading is viewed as a process involving the text, reader, and context.

\subsection{Recent Evaluations and Discussions of the SVR}

Several recently conducted large-scale, empirical studies provide further evidence for the efficacy of the SVR. Specifically, these investigations have explored the predictive ability of prekindergarten skills to third grade reading comprehension [17], the individual and joint contributions of decoding and language comprehension to reading comprehension among third through fifth grade students, the developmental shift in relative importance of the two components across the grade levels [18], and the impact of text variation and the role of fluency among typically developing and struggling middle school readers [19]. Findings of these studies have also offered scholars the opportunity to reflect on the SVR more than 30 years after its inception and comment on the educational implications of the model [13], the impact of type of assessments used to measure comprehension [20], and the contributions of the model to advances in the field [21]. In commenting on its history, Snow [20] suggested, "Few hypotheses in the field of literacy have proven as robust as the Simple View of Reading" (p. 313).

As a result of recent research findings, more nuanced descriptions of the components of the SVR have emerged. We found Kirby's and Savage's [12] review of the empirical evidence associated with the SVR, and their commentary regarding the ability to explain the complexities of reading using this model, as well as Hoover's and Tunmer's [13] discussions of recent research findings, particularly salient to these discussions. In the area of decoding specifically, information from the dual route model of reading (e.g., [22]), in which both lexical (e.g., memory for previously seen written words) and non-lexical (e.g., grapheme-phoneme correspondences) routes contribute to word reading abilities, has influenced understandings of the skills readers employ to read both phonetically regular and irregular words. Similarly, research findings indicating the strong association between phonological sensitivity (i.e., phonological and phonemic awareness) and subsequent decoding skills have provided valuable insights into precursor phonological abilities associated with early decoding skills (e.g., [23-26]).

Research has also highlighted the importance of additional cognitive activities and prerequisite skills associated with the decoding domain such as RAN, or the ability to name objects represented by pictures, colors, letters, or digits presented in random order. Phonological memory, which is the ability to remember spoken information for a short period of time, has also been associated with decoding and other early literacy abilities. Finally, alphabet knowledge, or the understanding of the names and sounds associated with printed letters, is considered a precursor skill that is correlated with later measures of literacy development (e.g., [12,27]).

In addition to the aforementioned skills, the reciprocity between the development of alphabet knowledge and phonological abilities has been discussed (e.g., [28,29]). Specifically, it has been hypothesized that alphabet knowledge furthers children's understandings of how spoken language is represented in print [30] and illustrates that words are comprised of smaller units [31]. Because phonological information is included in all letters except the consonant $w$ and the short vowel sounds (e.g., the letter name $\mathrm{b}$ contains the $/ \mathrm{b} /$ sound as in $/ \mathrm{b} / / \mathrm{e} /$, the letter name $\mathrm{m}$ contains the $/ \mathrm{m} /$ sound as 
in $/ \breve{\mathrm{e}} / / \mathrm{m} /)$, it has been suggested that print and alphabet experiences contribute to the development of the phonological skills that support later decoding abilities (e.g., [32,33]).

A recent critique of the SVR is that it focuses primarily on reader-based variables and does not take into account variability associated with text ([19] see also [20,21]). Furthermore, it has been suggested that the SVR is more a conceptual model of reading rather than a developmental or statistical one. To address these limitations, a Complete View of Reading (CVRi) has been proposed, whereby oral reading fluency serves as a proxy for reading comprehension. It has been suggested that the CVR $i$ expands on the foundation of the SVR and offers a more comprehensive model of reading by considering the impact of text features (e.g., complexity, genre) on comprehension abilities [19]. It is interesting to note that the CVR $i$ more closely aligns with Chall's [15] schema, as well as the findings of the National Reading Panel (NRP) [34], which recognize the key role reading fluency plays in serving as a bridge between decoding and reading comprehension abilities.

While potential limitations to the SVR have been noted, and adjustments to the framework have been offered to clarify and expand its components, findings of research investigations have consistently illustrated that the core principles of the model (i.e., decoding, language comprehension) represent a robust hypothesis for understanding the development of reading comprehension abilities. In fact, we would suggest that the components of the SVR are echoed in both existing (e.g., Chall [15]) and emerging (e.g., CVR $i$ [19]) models of reading development, as well as the findings of large-scale research analyses (e.g., NELP [27], NRP [34],), thereby lending further support for the importance of both skills in the reading process.

\section{Historical Research Evidence in Reading and Deafness}

Large-scale data collection on the academic achievement of deaf students in the United States began approximately 50 years ago, with the Stanford Achievement Test (SAT) used as an outcome measure. At the time, the typical administration procedures of this assessment required students to take the test corresponding to their current grade placement. For example, a student enrolled in fourth grade would be required to take the fourth-grade test. However, given the history of achievement challenges experienced by deaf learners, a special version of the assessment was developed in 1974, the Stanford Achievement Test for Hearing Impaired (SAT-HI). While the test questions and format of the SAT-HI remained consistent with the original SAT measure, a screening assessment was created so that test levels could be matched to students' current level of performance rather than grade level. For example, a student enrolled in fourth grade who was achieving below grade level expectations could take a lower-level test, such as the one intended for second-grade students [1].

Beginning in 1974 and continuing through 2003, five large-scale studies were conducted using the SAT-HI, with normative data regarding student performance developed as a result of each investigation. Data from nearly 7000 students ages 8 through 18 comprised the special norming sample in 1974, whereas the normative data from 2003 represented approximately 3500 students. Considering the data for the reading comprehension subtest across 11 cohorts of students over time (i.e., students age 8 through 18 from 1974 to 2003), performance levels were shown to increase slightly as a function of age. However, the median grade equivalent never exceeded the fourth grade level for any given cohort. These findings led Qi and Mitchell [1] to conclude, "there has been little or no change in the central tendency of academic achievement among the deaf and hearing student population over the last three decades" (p. 7).

In addition to the results for the reading comprehension subtest, Traxler [35] also reported data for the reading vocabulary subtest from the SAT-HI norming study conducted in 1996. In this investigation, four performance levels (i.e., below basic, basic, proficient, advanced) were used to interpret the findings for deaf learners relative to hearing students. For the reading comprehension subtest, the median score (50th percentile) for the entire group of deaf students ages 8 through 18 fell within the below basic level, whereas data for those students achieving at the 80th percentile revealed 
performance within the basic level. Findings of the reading vocabulary subtest indicated a similar pattern of performance.

\section{Historical Research Evidence and the SVR}

One of the challenges in interpreting the historical achievement data in the context of the SVR is that the SAT-HI only included data on the product of reading (i.e., comprehension, reading vocabulary) and not the components skills of decoding and language comprehension. While these findings do demonstrate a significant achievement gap between deaf and hearing readers, the underlying cause of reading difficulties-decoding, language comprehension, or a combination thereof-remained a question. Within the field of deafness, discussions of reading frequently become an either-or debate, with phonological decoding skills pitted against language abilities in determining which is critical to the overall developmental process and/or responsible for achievement outcomes (e.g., [2,36,37] see also [5] for discussion). In many ways, these debates parallel those that began in the field of reading more than a half-century ago [14], and those that were prominent during the time the SVR was proposed.

In response to these debates, supporters of the QSH have asserted that phonological skills are a necessary component of reading for deaf individuals but have also recognized these skills alone are not sufficient for reading comprehension to occur [3]. These assertions clearly align with the premise of the SVR. In fact, several research teams have explicitly referenced the SVR or similar cognitive models when discussing phonological skills as essential components of both early and conventional reading for deaf learners (e.g., [38-40]). The alternative view, in which phonological skills are not considered a necessary element (e.g., [37]), has been critiqued because it has not been contextualized within an extant model of reading, and an alternative hypothesis of development has not been empirically demonstrated [3].

When applying the SVR equation $\mathrm{R}=\mathrm{D} \times \mathrm{C}$, it can be argued that in order for reading comprehension to occur, readers must first be able to access the text through the decoding process. Although not explicitly discussed as a feature of the SVR, it is also true that individuals must possess a threshold of language comprehension abilities before decoding even becomes a goal. In fact, it is widely accepted that knowledge of syntax, words, and the nature of words (e.g., rhyme, alliteration) are pre-reading abilities that form the foundation for, and have a substantial influence on, early decoding skills (e.g., $[15,27,34]$. We would suggest that this prerequisite level of communicative competence in the language to be read (e.g., English) is assumed in a conceptual model of reading, particularly when applied to hearing readers. Gough's and Tunmer's [11] discussion of the ability of readers to activate accurate meanings within the mental lexicon as part of the decoding process further supports this assumption.

However, we recognize that some deaf children may not possess the essential language foundations at the onset of formal decoding instruction, which typically begins in kindergarten. This includes deaf children whose first language is not English, but rather a natural signed language (e.g., American Sign Language) or another spoken language (see [39] for discussion). From the perspective of the SVR, it is likely that this subgroup of deaf learners would evidence performance similar to the students described as having a "garden variety reading disability" [11] (p. 8), in which barriers to reading comprehension result from challenges with both decoding and language comprehension.

While the language delays and deficits of deaf learners have been widely accepted and are well documented in the literature (e.g., [41]), the role of phonological decoding in reading for deaf learners is one of the most fiercely debated topics in the field (see [2,3,5]). In fact, criticisms of the QSH have focused "mostly on the role of phonology in the development of reading, particularly in the learning to read period" ([10] p. 17). From the perspective of the SVR, "reading comprehension increases linearly with increases in either decoding or linguistic comprehension except where skill in one component is nil." [13] (p. 308). The notion that an absence of skill in the decoding domain, or a lack of instructional focus on this component, largely contributes to the difficulties deaf learners experience in attaining 
age-appropriate reading outcomes has been the focus of many discussions in reading and deafness in recent years (see $[5,39,40]$ for discussions). Therefore, our discussion of current research evidence will focus primarily on the phonological aspects of reading development and instruction. While not to diminish the critical role of language as a pre-reading ability and a necessary component for reading comprehension, the rationale for this decision is guided by our interpretation of the SVR equation, whereby automatic and accurate word decoding precedes the activation of language comprehension abilities in the process of reading comprehension.

\section{Current Research Evidence}

When considering the current research evidence regarding the phonological aspects of reading development and instruction, we relied on the studies identified and findings summarized within three recent reviews of the literature published in the last five years. This includes a qualitative meta-analysis [42], a standards-based examination of intervention research [43], and a review of reading comprehension and phonics studies employing correlational analyses [44]. Because our primary goal was to comment on existing evidence in reading and deafness within the context of the SVR framework, we did not consider it necessary to conduct our own meta-analysis of the research. In fact, we chose to rely on the aforementioned reviews because they examined recently published works, employed rigorous standards in terms of search procedures and reporting of findings, and represented a range of research methodologies. Collectively, we would suggest that these publications represent the current state of the evidence on this topic.

\subsection{Qualitative Meta-Analysis}

Even though several scholars in the field have contextualized their intervention research within a conceptual model of development (e.g., [38-40]), the findings of the NRP [34] are more frequently referenced as a foundation for this work. This situation may not differ substantially from the field of reading more broadly, as it has been suggested that curricular standards tend to drive instruction more frequently than cognitive models [13]. Schirmer and McGough [45] are credited as the first in the field to explore the applicability of the findings from the NRP, including phonemic awareness, phonics, fluency, vocabulary, and comprehension, to reading development and instruction for deaf learners. In their review of 67 studies conducted between 1970 and 2001, they identified only one study that examined phonologically based instruction. However, due to inadequate descriptions of the methodology and results, this investigation was characterized by Schirmer and McGough [45] as one "with serious flaws" (p. 89).

A series of four meta-analyses by Luckner and colleagues were also conducted that explored the areas recommended by the NRP [34]. These included an examination of reading research across all five areas of instruction in general [46], as well as in the components of reading fluency [47], vocabulary [48], and reading comprehension [49] specifically. A meta-analysis of 57 studies in reading and deafness, 25 of which measured the relationship between participants' phonological coding and awareness skills and reading abilities, was also completed [36].

The findings of the six aforementioned publications were among the 11 qualitative and 39 quantitative meta-analyses of reading research systematically reviewed across three groups of learners: (1) Monolingual hearing students, (2) special education students and English language learners (ELL), and (3) deaf students. In their conclusion regarding the category of alphabetics (i.e., phonemic awareness and phonics), Wang and Williams [42] suggested that the research with monolingual, special education, and ELL hearing students provided support for phonemic awareness and phonics as part of reading instruction, particularly in prekindergarten through first grade. However, they also acknowledged that the research conducted with deaf learners, "was too limited or too methodologically weak to permit conclusions to be drawn" (p. 342). In discussing the implications for this finding, a call for an increased number of quality studies was made, especially those employing designs in which causality can be determined. 


\subsection{Standards-Based Examination of Intervention Research}

The evidence-based standards published by the Council for Exceptional Children (CEC, [50]) were recently applied to the body of intervention research conducted in reading and deafness between 2000 and 2016 [43]. The CEC standards include a set of quality indicators to evaluate studies using group comparison (e.g., experimental, quasi-experimental, regression discontinuity) and single-subject designs. The eight quality indicators of these CEC standards are applied to an investigation to determine the thorough reporting of key study elements (e.g., context, participant, intervention agent, description of practice, implementation fidelity) and to examine the study's methodological rigor (e.g., internal validity, outcome measures, data analysis). In accordance with the CEC procedures, studies are grouped for analysis based on target outcomes and are classified in one of five categories (i.e., evidence-based, potentially evidence-based practice, mixed evidence, insufficient evidence, or negative effects) based on factors such as the number of studies, type of study design, number of participants, and study effects.

In this analysis, the categories associated with decoding interventions included explicit phonological/phonemic awareness and phonics instruction, and one titled 'comprehensive', which was used to capture studies of specific reading approaches or curricula that addressed and measured more than one area of instruction (e.g., decoding and vocabulary). Because several of the explicit phonological/phonemic awareness and phonics studies used the Visual Phonics instructional tool as part of intervention, the category was divided in two to account for those that used the tool and those that did not [43]. Visual Phonics is a multisensory system designed to provide visual, tactile, and kinesthetic information regarding the production of individual phonemes. The Visual Phonics system is comprised of 46 hand gestures and associated written symbols and is frequently used to supplement phonologically-based reading instruction for deaf learners, particularly for those students with limited auditory access and/or the ability to differentiate phonemes produced in a similar manner (e.g., phonemes /t/ and /d/) (see [39,40] for discussions).

Of the 30 total intervention studies identified for the standards-based examination, six investigations of phonological skills employed either a group comparison or single-subject design. Three of these studies, one group comparison [51] and two single-subject [52,53], were identified in the category of phonological instruction supplemented by Visual Phonics. Based on the positive effects obtained in each of these studies, coupled with the study design and number of participants, this category of instruction was identified as potentially evidence-based. Two of the studies, both using single-subject design [54,55], comprised the phonological instruction without Visual Phonics category. Due to the number of studies and the fact that mixed results were obtained in one investigation, the CEC [50] mixed evidence classification was assigned to this practice. Finally, a phonologically focused reading curriculum included in the comprehensive category, Foundations for Literacy, was evaluated by one study [38] and identified as a potentially evidence-based practice as a result of the CEC evidence-based practices analysis [43].

\subsection{Correlational Research}

In a recent review of correlational research, Luft [44] summarized the findings of 28 studies of reading comprehension and phonics. Research supporting the role of phonologically related abilities across alphabetic languages, as well as the relatively few studies available in the low incidence disability category of deafness, was provided as the rationale for including studies within the review that examined languages other than English. Specifically, studies that examined the correlation between constrained reading skills (e.g., orthographic awareness, phonemic awareness, phonological skills), and the unconstrained area of reading comprehension, were examined. Because it was unclear whether phonemic awareness (PA) was measured without the use of print in some of the reviewed studies, this ability was combined with measures of phonological skills involving print (PS) in order to create one category (PA/PS) to discuss findings across investigations. 
In discussing the findings of studies examining PA/PS and orthographic awareness (OA) skills, Luft [44] was particularly interested in exploring the type of measures used and the administration timing of these measures across the body of correlational studies. Findings suggested that a wide range of assessments were used to assess PA/PS and OA skills including those measuring phonological and phonemic awareness abilities (e.g., rhyme decision and generation, syllabic similarity, phoneme detection, blending and matching), the alphabetic principle (e.g., phoneme-grapheme correspondences), decoding (e.g., reading words, non-words, and word chains), and encoding (e.g., spelling). Additional measures assessing cognitive tasks (e.g., RAN of letters and numbers) were also included in some studies. Similarly, measures used to assess reading comprehension varied across word (e.g., word identification, pseudoword reading, word chains), sentence (e.g., cloze), and passage (e.g., cloze, reading selections followed by questions) level assessments.

When examining studies, Luft [44] considered the age at which PA/PS and OA skills are typically the primary focus of development and instruction, between six- to eight-years-old, and defined this as the target age range for participants in studies. Across the 28 studies, she identified only three investigations examining the development of skills among participants within this age range exclusively [56-58]. The remaining studies involved participants outside of the age range entirely $(n=11)$ or a combination of participants both within and outside the target age range $(n=14)$. In considering the results for PA/PS skills across all investigations, 17 studies reported significant correlations with reading comprehension. Another five studies included in the review reported significant correlations between OA and reading comprehension.

Issues regarding both type and timing of measures across areas of reading that were identified as a result of this review undoubtedly contributed to the mixed findings obtained across studies. In fact, this led Luft [44] to conclude, " ... that the varying measures likely obscured patterns as well as differences among the reading constructs and PA/PS and OA subskills. This was further complicated by participant age effects on variability across early, constrained and later, unconstrained skills." (p. 159).

\subsection{Current Research Evidence and the SVR}

While the recently published reviews examining the phonological aspects of reading development and instruction for deaf learners revealed some mixed findings, it could be argued that the research to date points to the fact that successful deaf readers have control of phonological skills, and that there is no compelling empirical evidence to suggest that deaf learners can become proficient readers without them (see $[3,5,42]$ for discussions). Given the long-standing and on-going debates in the field, we find the increased research attention in this area encouraging. A particular strength of the current body of evidence is that a variety of research methodologies have been employed to examine issues of phonological skill development, and efforts have been made to implement instructional interventions with deaf learners that target these skills. However, despite these developments, we also acknowledge that more rigorous investigations of this topic are needed in order to provide further support for the role of phonological skills in reading for deaf learners.

One of the on-going challenges in interpreting the findings of phonologically based studies in the field of deafness relates to the terminology used to describe these skills and to categorize assessments used to measures them, as it does not necessarily reflect those used in the general field of reading. For example, the term phonological awareness is typically used to describe a broad skill that involves manipulating elements of oral language (e.g., rhyming, syllable blending and segmenting), whereas phonemic awareness refers to the specific ability to manipulate individual sounds within words. In regards to skills that involve print, the alphabetic principle refers to the understanding of the systematic and predictable relationship between letters and sounds, and phonics is used to describe the ability to use this knowledge to read (decode) and spell (encode) words. As previously indicated, it has been suggested that combining these abilities across categories of skills may conflate or obfuscate the findings obtained (see $[5,44]$ for discussions). 
In the general field of reading, latent variable models are frequently used to evaluate the adequacy of the SVR. In investigations of this type, multiple measures of each construct are employed to determine the influences of decoding and language comprehension on reading comprehension. For example, in a recent investigation exploring the ability to predict third grade reading comprehension abilities from prekindergarten skills, 11 measures assessing language abilities (e.g., vocabulary, grammar, and discourse-level language) and four measures of code-related skills (e.g., letter knowledge, phonological awareness, RAN) were used to assess the skills of the prekindergarten participants [17]. In order to confirm the applicability of the SVR to reading for deaf learners and draw firm conclusions regarding the QSH [10], studies that employ similar study designs and measures would need to be conducted. In this way, we agree with Luft's [44] comment that sophisticated causal modeling may serve to overcome the current limitations of correlational research.

Of the 30 intervention studies Trezek and Wang [43] identified for their analysis, $12(40 \%)$ examined the area of decoding and eight included the Visual Phonics supplement as a component of the intervention. The inclusion of the Visual Phonics instructional tool suggests that researchers recognize that this type of instruction has the potential to benefit a wide range of deaf learners, including those who may require differentiated access to the phonology of English. However, only half of these studies represented group comparison and single-subject design studies in which causality could be inferred. In addition, the majority of these studies drew conclusions based on researcher-developed measures of decoding and word-level skills and none of them examined the impact of these skills on reading comprehension outcomes. Furthermore, at the time the review was conducted, only one study was identified that focused exclusively on the development of phonological or phonemic awareness abilities among deaf learners [55]. This stands in contrast to the significant number of studies in both general and special education examining these skills in addition to those associated with decoding.

\section{Discussion and Recommendations}

The SVR [11] provides a robust hypothesis for explaining the reading development of a wide range of learners and has the potential to inform our understandings of the QSH [10] for deaf learners. Supporters of the SVR framework acknowledge that both decoding and language comprehension are essential elements of reading comprehension and recognize the differential and relative contributions of these skills across grade levels. As such, reading is not viewed as an either-or debate between decoding skills and language comprehension abilities. Rather, reading comprehension is seen as a product of the two components, in which neither decoding or language comprehension alone is sufficient [3].

For all readers, language forms the foundation for reading [15]. This fact may be particularly salient for deaf readers who have historically experienced challenges in acquiring competence in the face-to-face form of the language that is required for reading. Furthermore, it can be argued that several abilities often associated with the decoding domain that involve understanding of the nature of words, such as phonological and phonemic awareness, may actually be more closely associated with language comprehension abilities. These skills, along with general language abilities that involve the understanding of English words and syntax, are seen as critical elements for both early and conventional reading abilities (see [39] for discussion of deaf learners).

The findings of this review of the current evidence offer several implications for research and practice. To foster a research-to-practice orientation that recognizes the connection between the two in the process of identifying evidence-based practices, the implications for future directions will be discussed collectively. In light of the information presented and discussed, the following recommendations for future research and practice in reading and deafness are offered:

- Researchers should employ structural equation modeling to test various hypotheses of reading development to examine the applicability of the SVR to reading and deafness. As part of a recent investigation, Chui [17] offered several hypotheses to explain the relations between language comprehension abilities and decoding skills that may serve to inform hypotheses to be tested with deaf learners. 
- Studies with deaf learners should be conducted within the appropriate target age range for the constructs under investigation and include a longitudinal component in order to examine participants' progress over time (e.g., preschool through third grade). Within these and all investigations, the demographic characteristics (e.g., degree of hearing loss, use of hearing technologies, educational placement, communication modality) of study participants should be thoroughly described in order to ensure the generalizability of findings.

- Given the availability of standardized measures of decoding, language comprehension, and reading comprehension, assessments of this type should be employed in the research whenever possible. This will allow researchers to compare reading outcomes to normative data as well as across investigations. Using these assessments will also permit researchers to replicate studies, thereby increasing the number of participants assessed under similar conditions. This would be particularly useful in terms of conducting research with a low incidence population of students such as deaf learners, since achieving adequate sample sizes presents an on-going challenge in conducting research in the field. In relation to phonological abilities specifically, the use of standardized assessments may also foster the use of appropriate terminology to characterize skills, describe assessments, and report findings.

- Future studies of phonics interventions should examine not only the immediate effects of instruction on word-level reading skills but also the longitudinal impact on reading comprehension outcomes.

- It is recommended that future intervention research studies examine the implementation of phonological and phonemic awareness instruction, particularly among deaf children at the prekindergarten level. It is further suggested that existing curricula or readily available interventions (e.g., commercially available) be used in order to permit study replications.

\section{Conclusions}

The present review examining the state of evidence in reading and deafness provides interesting insights that can inform both research and practice. Given the historical reading outcomes documented for deaf learners, coupled with a relatively weak methodologically research base, future investigations should focus on identifying and empirically evaluating conceptual models of development and instruction for this population of students. We would suggest that the SVR [11] provides an appropriate framework for exploring the individual and joint contributions of decoding skills and language comprehension abilities to reading comprehension for this population of students and complements Hanson's [4] work examining the influences of language and phonology on the reading abilities of deaf individuals. Testing various hypotheses within the framework of the SVR would also allow researchers to evaluate the QSH [10] and identify similarities as well as potential differences in the reading development of deaf learners.

From a research-to-practice orientation, intervention research should focus on areas identified as a result of evaluating conceptual models such as the SVR [11]. Given the reciprocity between research and practice, the findings of these investigations can serve to further inform these models, thereby offering a robust framework for future research and practice in the field. This work would be particularly timely, as current large-scale data documenting the reading outcomes for deaf learners were collected more than 20 years ago [35]. As such, these data do not represent the impact of two major advances in the field-the introduction of universal newborn hearing screening and improved hearing technologies, including cochlear implantation. Recent findings suggest that both early and conventional literacy outcomes have improved as a result of these advances, with a significant number of deaf students reading at age-appropriate levels $[59,60]$. However, findings of the present review of the evidence suggest that additional investigations, particularly those that employ robust methodologies, examine precursor abilities such as phonological and phonemic awareness, and track children's achievement over time, are clearly warranted. 
Author Contributions: Conceptualization, B.T. and C.M.; Writing-original draft preparation, B.T.; Writing-review and editing, B.T. and CM.

Funding: This research received no external funding.

Conflicts of Interest: The authors declare no conflict of interest.

\section{Notes on Terminology}

We use the term deaf to refer to any individual identified with a hearing loss, from mild
to profound, irrespective of the use of amplification. For instance, individuals with
cochlear implants are regarded as deaf. We are also not making a distinction between
deaf and Deaf, as we do not consider this difference germane to our view of the
development of reading.
When the term 'oral language' is used, it is done so to reflect the terminology employed
in the original source (e.g., National Early Literacy Panel, a published study, etc.). This
term is often used synonymously with 'spoken language' in the broader literature in
the field of literacy. It is only in the field of deafness in which the distinction between
oral and spoken language merits attention.

\section{References}

1. Qi, S.; Mitchell, R.E. Large scale academic achievement testing of deaf and hard-of-hearing students: Past, present, and future. J. Deaf Stud. Deaf Educ. 2012, 17, 1-18. [CrossRef] [PubMed]

2. Allen, T.; Clark, M.D.; del Giudice, A.; Koo, D.; Lieberman, A.; Mayberry, R.; Miller, P. Phonology and reading: A response to Wang, Trezek, Luckner, and Paul. Am. Ann. Deaf 2009, 154, 338-345. [CrossRef] [PubMed]

3. Paul, P.V.; Wang, Y.; Trezek, B.J.; Luckner, J.L. Phonology is necessary, but not sufficient: A rejoinder. Am. Ann. Deaf 2009, 154, 346-356. [CrossRef] [PubMed]

4. Hanson, V. Phonology and reading: Evidence from profoundly deaf readers. In Phonology and Reading Disability: Solving the Reading Puzzle; Shankweiler, D., Liberman, I., Eds.; University of Michigan Press: Ann Arbor, MI, USA, 1989; pp. 69-89.

5. Mayer, C.; Trezek, B.J. Is reading different for deaf individuals? Re-examining the role of phonology. Am. Ann. Deaf 2014, 159, 359-371. [CrossRef] [PubMed]

6. Paul, P. Qualitative-similarity hypothesis. In Progress in Education; Nata, R., Ed.; Nova Science: New York, NY, USA, 2010; pp. 1-31.

7. Paul, P. Qualitative similarity hypothesis. In Deaf Epistemologies: Multiple Perspectives on the Acquisition of Knowledge; Paul, P., Moores, D., Eds.; Gallaudet University Press: Washington, DC, USA, 2012; pp. $179-198$.

8. Paul, P.; Lee, C. Qualitative-similarity hypothesis. Am. Ann. Deaf 2010, 154, 456-462. [CrossRef]

9. Paul, P.; Wang, Y. Literate Thought: Understanding Comprehension and Literacy; Jason \& Bartlett Learning: Sudbury, MA, USA, 2012.

10. Paul, P.; Wang, Y.; Williams, C. Deaf Students and the Qualitative Similarity Hypothesis: Understanding Language and Literacy Development; Gallaudet University Press: Washington, DC, USA, 2013.

11. Gough, P.B.; Tunmer, W.E. Decoding, reading, and reading disability. Remedial Spec. Educ. 1986, 7, 6-10. [CrossRef]

12. Kirby, J.R.; Savage, R.S. Can the simple view deal with the complexities of reading? Literacy 2008, 42, 75-82. [CrossRef]

13. Hoover, W.A.; Tunmer, W.E. The Simple View of Reading: Three assessments of its adequacy. Remedial Spec. Educ. 2018, 39, 304-312. [CrossRef]

14. Chall, J.S. Learning to Read: The Great Debate; McGraw-Hill: New York, NY, USA, 1967.

15. Chall, J.S. Stages of Reading Development; McGraw-Hill: New York, NY, USA, 1983.

16. Paris, S.G. Developmental differences in early reading skills. In Handbook of Early Literacy Research: Volume 3; Neuman, S.B., Dickinson, D.K., Eds.; Guilford Press: New York, NY, USA, 2011; pp. 228-241.

17. Chiu, Y.D. The simple view of reading across development: Prediction of grade 3 reading comprehension from prekindergarten skills. Remedial Spec. Educ. 2018, 39, 289-303. [CrossRef] 
18. Lonigan, C.J.; Burgess, S.R.; Schatschneider, C. Examining the Simple View of Reading with elementary school children: Still simple after all these years. Remedial Spec. Educ. 2018, 39, 260-273. [CrossRef]

19. Francis, D.J.; Kulesz, P.A.; Benoit, J.S. Extending the Simple View of Reading to account for variation within readers and across texts: The Complete View of Reading (CVRi). Remedial Spec. Educ. 2018, 39, 274-288. [CrossRef] [PubMed]

20. Snow, C.E. Simple and not-so-simple views of reading. Remedial Spec. Educ. 2018, 39, 313-316. [CrossRef]

21. Catts, H.W. The Simple View of Reading: Advancements and false impressions. Remedial Spec. Educ. 2018, 39, 317-323. [CrossRef]

22. Castles, A. The dual route model and the developmental dyslexias. Lond. Rev. Educ. 2006, 4, 49-61. [CrossRef]

23. Burgess, S.R.; Lonigan, C.J. Bidirectional relations of phonological sensitivity prereading abilities: Evidence from a preschool sample. J. Exp. Child Psychol. 1998, 70, 117-141. [CrossRef] [PubMed]

24. Lonigan, C.J.; Burgess, S.R.; Anthony, J.L. Development of emergent literacy and early reading skills in preschool children: Evidence from a latent-variable longitudinal study. Dev. Psychol. 2000, 36, 596-613. [CrossRef]

25. Wagner, R.K.; Torgesen, J.K.; Rashotte, C.A. Development of reading-related phonological processing abilities: New evidence of bidirectional causality from a latent variable longitudinal study. Dev. Psychol. 1994, 30, 73-87. [CrossRef]

26. Wagner, R.K.; Torgesen, J.K.; Rashotte, C.A.; Hecht, S.A.; Barker, T.A.; Burgess, S.R.; Donahue, J.; Garen, T. Changing relations between phonological processing abilities and word-level reading as children develop from beginning to skilled readers: A 5-year longitudinal study. Dev. Psychol. 1997, 33, 468-479. [CrossRef]

27. National Early Literacy Panel. Developing Early Literacy: Report of the National Early Literacy Panel; The National Institute for Literacy: Washington, DC, USA, 2008.

28. de Jong, P.F.; Olson, R.K. Early prediction of letter knowledge. J. Exp. Child Psychol. 2004, 88, $254-273$. [CrossRef]

29. Murray, B.A.; Stahl, S.A.; Ivey, M.G. Developing phoneme awareness through alphabet books. Read. Writ. 1996, 8, 307-322. [CrossRef]

30. Phillips, B.M.; Torgesen, J.K. Phonemic awareness and reading: Beyond the growth of initial reading accuracy. In Handbook of Early Literacy Research: Volume 2; Dickinson, D.K., Neuman, S.B., Eds.; The Guilford Press: New York, NY, USA, 2006; pp. 101-112.

31. Burgess, S.R. The development of phonological sensitivity. In Handbook of Early Literacy Research: Volume 2; Dickinson, D.K., Neuman, S.B., Eds.; The Guilford Press: New York, NY, USA, 2006; pp. 90-100.

32. Ehri, L.C.; Roberts, T. The roots of learning to read and write: Acquisition of letters and phonemic awareness. In Handbook of Early Literacy Research: Volume 2; Dickinson, D.K., Neuman, S.B., Eds.; The Guilford Press: New York, NY, USA, 2006; pp. 113-131.

33. Treiman, R.; Tincoff, R.; Rodriguez, K.; Mouzaki, A.; Francis, D. The foundations of literacy: Learning the sounds of letters. Child Dev. 1998, 69, 1524-1540. [CrossRef] [PubMed]

34. National Reading Panel. Report of the National Reading Panel: Teaching Children to Read-An Evidence-Based Assessment of the Scientific Research Literature on Reading and Itsimplications for Reading Instruction; National Institute for Literacy at EDPubs: Jessup, MD, USA, 2000.

35. Traxler, C. The Stanford Achievement Test, 9th edition: National norming and performance standards for deaf and hard of hearing students. J. Deaf Stud. Deaf Educ. 2000, 5, 337-348. [CrossRef] [PubMed]

36. Mayberry, R.; del Guidice, A.; Lieberman, A. Reading achievement in relation to phonological coding and awareness in deaf readers: A meta-analysis. J. Deaf Stud. Deaf Educ. 2001, 16, 164-188. [CrossRef] [PubMed]

37. Miller, P.; Clark, M.D. Phonemic awareness is not necessary to become a skilled deaf reader. J. Dev. Phys. Disabil. 2011, 23, 459-476. [CrossRef]

38. Lederberg, A.R.; Miller, E.M.; Easterbrooks, S.R.; Connor, C.M. Foundations for Literacy: An early literacy intervention for deaf and hard-of-hearing children. J. Deaf Stud. Deaf Educ. 2014, 19, 438-455. [CrossRef]

39. Mayer, C.; Trezek, B.J. Early Literacy Development in Deaf Children; Oxford University Press: New York, NY, USA, 2015.

40. Trezek, B.J.; Wang, Y.; Paul, P.V. Reading and Deafness: Theory, Research and Practice; Cengage Learning: Belmont, CA, USA, 2010.

41. Paul, P.V. Language and Deafness, 4th ed.; Jones and Bartlett Learning: Burlington, MA, USA, 2009. 
42. Wang, Y.; Williams, C. Are we hammering square pegs into round holes? An investigation of the metaanalyses of reading research with students who are d/Deaf or hard of hearing and students who are hearing. Am. Ann. Deaf 2014, 159, 323-345. [CrossRef] [PubMed]

43. Trezek, B.J.; Wang, Y. Evaluating evidence-based practices in reading interventions for deaf students. In Research in Deaf Education: Contexts, Challenges, and Considerations; Cawthon, S.W., Garberoglio, C.L., Eds.; Oxford University Press: New York, NY, USA, 2017; pp. 277-308.

44. Luft, P. Reading comprehension and phonics research: Review of correlational analyses with deaf and hard-of-hearing students. J. Deaf Stud. Deaf Educ. 2018, 23, 148-163. [CrossRef]

45. Schirmer, B.R.; McGough, S.M. Teaching reading to children who are deaf: Do the conclusions of the National Reading Panel apply? Rev. Educ. Res. 2005, 75, 83-117. [CrossRef]

46. Luckner, J.L.; Sebold, A.M.; Cooney, J.; Young, J., III; Muir, S.G. An examination of the evidence-based literacy research in deaf education. Am. Ann. Deaf 2006, 150, 443-456. [CrossRef]

47. Luckner, J.L.; Urbach, J. Reading fluency and students who are deaf or hard of hearing: Synthesis of the research. Commun. Disord. Q. 2012, 33, 230-241. [CrossRef]

48. Luckner, J.L.; Cooke, C. A summary of the vocabulary research with students who are deaf or hard of hearing. Am. Ann. Deaf 2010, 155, 38-67. [CrossRef]

49. Luckner, J.L.; Handley, C.M. A summary of the reading comprehension research undertaken with students who are deaf or hard of hearing. Am. Ann. Deaf 2008, 153, 6-36. [CrossRef]

50. Council for Exceptional Children. Council for Exceptional Children: Standards for evidence-based practices in special education. Except. Child. 2014, 80, 504-512. [CrossRef]

51. Trezek, B.J.; Malmgren, K.W. The efficacy of utilizing a phonics treatment package with middle school deaf and hard-of-hearing students. J. Deaf Stud. Deaf Educ. 2005, 10, 256-271. [CrossRef]

52. Beal-Alvarez, J.S.; Lederberg, A.R.; Easterbrooks, S.R. Grapheme-phoneme acquisition of deaf preschoolers. J. Deaf Stud. Deaf Educ. 2012, 17, 39-60. [CrossRef]

53. Tucci, S.L.; Easterbrooks, S.R. A syllable segmentation, letter-sound, and initial-sound intervention with students who are deaf or hard of hearing and use sign language. J. Spec. Educ. 2015, 48, 279-289. [CrossRef]

54. Bergeron, J.P.; Lederberg, A.R.; Easterbrooks, S.R.; Miller, E.M.; Connor, C.M. Building the alphabetic principle in young children who are deaf or hard of hearing. Volta Rev. 2009, 109, 87-119.

55. Miller, E.; Lederberg, A.; Easterbrooks, S. Phonological awareness: Explicit instruction for young deaf and hard-of-hearing children. J. Deaf Stud. Deaf Educ. 2013, 18, 206-227. [CrossRef]

56. Colin, S.; Magnan, A.; Ecalle, J.; Leybaert, J. Relations between deaf children's phonological skills in kindergarten and word recognition performance in first grade. J. Child Psychol. Psychiatry 2007, 48, 139-146. [CrossRef]

57. Kyle, F.E.; Harris, M. Concurrent correlates and predictors of reading and spelling achievement in deaf and hearing school children. J. Deaf Stud. Deaf Educ. 2006, 11, 273-288. [CrossRef]

58. Kyle, F.E.; Harris, M. Predictors of reading development in deaf children: A 3-year longitudinal study. J. Exp. Child Psychol. 2010, 107, 229-243. [CrossRef]

59. Cupples, L.; Ching, T.Y.C.; Crowe, K.; Day, J.; Seeto, M. Predictors of early reading skill in 5-year-old children with hearing loss who use spoken language. Read. Res. Q. 2013, 49, 85-104. [CrossRef]

60. Mayer, C.; Trezek, B.J. Literacy outcomes in deaf students with cochlear implants: Current state of the knowledge. J. Deaf Stud. Deaf Educ. 2018, 23, 1-16. [CrossRef]

(C) 2019 by the authors. Licensee MDPI, Basel, Switzerland. This article is an open access article distributed under the terms and conditions of the Creative Commons Attribution (CC BY) license (http://creativecommons.org/licenses/by/4.0/). 